\title{
NEOLIBERALISMO E AUSTERIDADE ECONÔMICA ENQUANTO FATORES CONDICIONANTES PARA A DESIGUALDADE NO BRASIL
}

\section{NEOLIBERALISM AND ECONOMIC AUSTERITY AS CONDITIONAL FACTORS FOR INEQUALITY IN BRAZIL}

Diana Melissa Ferreira Alves Diniz Pablo Sthefano Roque de Souza Bandeira

RESUMO: O presente trabalho tem como objetivo analisar as medidas governamentais de austeridade, no Brasil, enquanto fatores condicionantes para a desigualdade, face ao projeto constitucional de desenvolvimento. Para tanto, abordar-se-á, inicialmente, como se estabeleceu o neoliberalismo no país na década de 1990 e como tem se desenvolvido no período de 2016 até o presente momento. Em seguida, far-se-á uma explanação acerca dos reflexos de tais políticas na desigualdade de cunho social. E, por último, discutirse-á como elas contribuem para a desigualdade de gênero. Como problema central da pesquisa, questionouse: as medidas de austeridade econômica contribuíram para o aprofundamento da desigualdade no Brasil? Desta feita foi utilizado o método do materialismo histórico-dialético, contrapondo os aspectos políticos, sociais, jurídicos e econômicos da temática. A pesquisa, por sua vez, teve natureza bibliográfica pautada por livros, artigos, periódicos e documentários. E como síntese de resultados, observou-se que a agenda de austeridade econômica tem substancial contribuição no aumento da desigualdade brasileira.

Palavras-chave: Direito e Economia. Austeridade Econômica. Neoliberalismo. Desigualdade Social. Desigualdade de gênero.

ABSTRACT: This paper aims to analyze governmental austerity measures in Brazil, as conditioning factors for inequality, in view of the constitutional development project. To this end, it will be addressed, initially, how neoliberalism was established in the country in the 1990s and how it has developed in the period from 2016 to the present moment. Then, an explanation will be made about the effects of such policies on social inequality. And finally, it will be discussed how they contribute to gender inequality. As a central problem of the research, it was asked: did the measures of economic austerity contribute to the deepening of Inequality in Brazil? This time, the method of historical-dialectical materialism was used, contrasting the political, social, legal and economic aspects of the theme. The research, in turn, had a bibliographic nature based on books, articles, periodicals and documentaries. And as a synthesis of results, it was observed that the economic austerity agenda has a substantial contribution to the increase of Brazilian inequality.

Keywords: Law and Economics. Economic austerity. Neoliberalism. Social inequality. Gender inequality. 


\section{INTRODUÇÃO}

O neoliberalismo é a doutrina político-econômica que fundamentou as ações de diversas nações a partir dos anos 1970, sendo responsável por reorganização do capitalismo, naquele momento. Trata-se de um conceito polêmico, moldado mais como um campo de debate do que como um consenso. O termo passou a ser utilizado pejorativamente pelos críticos à desregulamentação do mercado, privatizações e desmonte do Estado de bem-estar, orientações típicas da Escola Austríaca, Escola de Chicago, e de representantes da London School of Economics e Manchester School, voltadas ao livre-mercado e contrárias ao intervencionismo estatal(ANDRADE, 2019).

As definições críticas sobre o neoliberalismo permeiam um conjunto inclusivo de alvos a serem combatidos nos níveis global e local, processos de mercadorização e espoliação, dispositivos financeiros, contábeis, econômicos, que se relacionam com estruturas normativas, de Estado, classes sociais, cidadania e democracia. As dimensões da economia globalizada, dos modos de regulação, do simbólico/ideológico e dos valores sociais e individuais se interrelacionam no que tange ao neoliberalismo, não podendo ser entendido em seu estado puro, mas entremeado nas formas socias e políticas (ANDRADE, 2019).

Durante a década de 1990, o Brasil foi o último país da América Latina a adotar a política econômica neoliberal. Recorreu-se, então, a um pacote de austeridade com o intuito de conter os fenômenos da hiperinflação e da instabilidade política (HERMIDA; LIRA, 2018). Ao final daquela década, percebeu-se que as medidas adotadas não surtiram o efeito esperado, tendo a conjuntura dos anos 2000 sido pautada pela aposta da superação da lógica neoliberal no continente latino-americano. O povo brasileiro, nesse sentido, elegeu um governo que se autodenominava progressista e buscou se distanciar, ainda que não totalmente, das determinações do Consenso de Washington (ANTUNES, 2005).

Ocorre que, ainda em 2008, uma nova crise econômica se espalhou pela Europa e América e a austeridade fiscal retornou ao centro do debate político-econômico, abrindo as portas para uma nova incursão neoliberal que tomou força em “terra brasilis" com o afastamento da Presidenta Dilma Rousseff e a ascensão de Michel Temer ao poder (HERMIDA; LIRA, 2018). Com a eleição de Jair Bolsonaro, em 2018, consolidouse uma agenda liberal voltada à limitação de políticas públicas sociais, com redução de investimentos e afrontas aos direitos do trabalhador (SAFATLE, 2019).

Faz-se necessário lembrar que nos contextos pátrios citados, o Estado brasileiro já se encontrava sob a vigência da Constituição Federal de 1988, que é objetiva ao estabelecer um projeto de desenvolvimento nacional, tanto por trazer como objetivos a redução da pobreza, das desigualdades regionais e sociais e a promoção do bem-estar de todos, quanto por fundar sua ordem econômica na valorização do trabalho humano, colocando que a livre-iniciativa também como fundamento, desde de que esteja em conformidade com a justiça social, para assegurar a todos uma existência digna (BRASIL, 1988).

Surge, portanto, o questionamento que norteou esse trabalho: as medidas de austeridade econômica são compatíveis com o projeto constitucional ou contribuíram para o aprofundamento da desigualdade no 
Brasil? A qual buscou-se responder ao longo do trabalho.

A metodologia desenvolvida e as técnicas de pesquisa utilizadas para a realização do presente trabalho foram escolhidas diante da observação da problemática e afim de resolver os objetivos enunciados. Para responder ao questionamento central do trabalho, recorreu-se ao método dialético de abordagem, no sentido de estabelecer uma reflexão crítica que pudesse realizar uma síntese dos aspectos econômicos, políticos, jurídicos e sociais da temática abordada, atentando-se para a totalidade e o movimento dos fenômenos (GUNSTIN; DIAS, 2006).

Dentro disso, será adotada a perspectiva marxista, na tentativa de transportar o método do Materialismo Histórico Dialético para a pesquisa jurídica, sabendo-se que: a herança de Marx exige reflexão crítica e ação revolucionária (PAULO NETTO, 2009). Assim, o que se busca, é realizar essa “análise histórica concreta". Através desse método, almeja-se uma interpretação dinâmica e totalizante da realidade investigada (MARX, 2008).

Mesmo no debate jurídico, faz-se necessária a análise das contradições da vida material (MARX, 2008). Há de se lembrar que os direitos previstos na perspectiva formal, a emancipação do Estado, não é uma emancipação consumada. A emancipação humana só se consuma quando o homem individual retoma em si o cidadão abstrato, reunindo na sua vida empírica, no seu trabalho, nas suas relações, tornando-se ser genérico, reconhecendo sua força própria como força social, não apartada da política. Emancipação humana é mais que um direito é a própria política (MARX, 2009).

Nesse sentido, a parceria intelectual e política de Marx e Engels produziu uma forma de produção de conhecimento para classes trabalhadoras em oposição ao domínio da ciência moderna permeada da sociabilidade burguesa. Orientou, assim, um método pautado pelas categorias: a totalidade, enxergando o objeto por meio de suas inúmeras determinações, negando a neutralidade do sujeito e não apartando os momentos político e econômico; a historicidade, apontando as formas políticas enquanto históricas, vinculadas a interesses materiais concretos do padrão de exploração; e a dialética, pautada nos movimentos de classes em luta no interior da sociedade em contradição (VALENÇA; ARAUJO; FREITAS, 2019).

Feitas essas considerações, o raciocínio dialético foi empregado no presente estudo da seguinte forma: a questão da desigualdade foi analisada em sua totalidade, atentando-se para o aspecto social, perfazendo-se os recortes da classe, do gênero e da raça. A historicidade, por sua vez, foi contemplada no sentido de que o desenvolvimento do neoliberalismo no Brasil foi situado na história, apoiando-se em fatos sociais e jurídicos com suas repercussões. Por fim, a questão do neoliberalismo, da austeridade e da desigualdade foi abordada de forma dinâmica, com base em dados históricos e estatísticos.

Como método de procedimento, valeu-se do histórico, para compreender o aprofundamento da desigualdade através da construção histórica brasileira em relação a ordem mundial que se desenvolveu. Pautou-se, pois, tanto por teóricos de viés Marxista, quanto por teorias mais contemporâneas da seara do Direito e Economia, dentro da vertente do Direito, Economia e Desenvolvimento (GUNSTIN; DIAS, 2006).

Em relação à vertente teórico-metodológica da pesquisa social aplicada, a pesquisa seguirá a linha 
crítico-metodológica, através da vertente jurídico-sociológica, compreendendo, assim, o Direito como uma rede complexa de linguagens e significados, preocupando-se com as suas relações contraditórias estabelecidas com os demais campos como o sociocultural e o econômico (GUNSTIN; DIAS, 2006).

Ainda em relação a pesquisa, será teórica e, quanto à forma de abordagem do problema, será qualitativa, eis que orientada por um vínculo indissociável entre o mundo objetivo e subjetividade que não pode ser trazida meramente em números, sendo atribuídos significados aos fenômenos observados, ainda que a reflexão aborde alguns números e estatísticas (GIL, 2008).

Acerca dos procedimentos técnicos, a pesquisa será bibliográfica, tomando por principais fontes livros, revistas, publicações em periódicos e artigos científicos, jornais, teses, dissertações, documentários e internet. A pesquisa será também documental, por meio de fontes de primeira e segunda mão(GIL, 2008).

Dentro disso, realizou-se uma explanação acerca da agenda liberal brasileira na década de 1990 e sua retomada a partir de 2016, através de digressões acerca de três marcos considerados característicos dessa nova fase: a Emenda Constitucional do teto dos gastos, a reforma trabalhista e a reforma da previdência e como isso gerou consequência na seara social.

Prosseguiu-se na temática tratando da influência das políticas de austeridade na desigualdade de gênero, tema que se mostra fundamental, diante da perspectiva crítica de desenvolvimento.

Desta feita, foi possível obter como resultado a compreensão de que as incursões neoliberais nos diferentes contextos afetaram os investimentos sociais no país e aprofundaram o fosso da desigualdade estrutural brasileira, processo que atinge de forma os gêneros e, dentre deles, as classes e raças, de forma diferenciada.

\section{INCURSÕES NEOLIBERAIS NO BRASIL PÓS CONSTITUIÇÃO DE 1988}

A seção que segue pretende realizar um apanhado histórico das agendas neoliberais do Brasil, após a promulgação da Constituição de 1988, entabulando uma reflexão a respeito de sua relação com o projeto de desenvolvimento estabelecido na Lei Maior.

O Brasil, isto é, o conjunto dos aspectos territoriais, populacionais, econômicos, sociais, políticos e culturais brasileiros, foram conformados em meio a um processo marcado fundamentalmente por quatro características: a dependência externa, a desigualdade social, a democracia oligárquica e o desenvolvimento limitado. O centro dinâmico da economia nacional é mantido no exterior e as tentativas de alteração desse panorama culminaram em diferentes alianças entre forças externas e internas para manter os mecanismos de dependência. A forma de reprodução dependente aprofunda a desigualdade social que permeia a história, colocando classes exploradas e dominantes em oposição. Essas contradições brasileiras determinam um padrão de desenvolvimento limitado, dado por saltos e inferior às potencialidades do país (POMAR, 2017).

Em vista disso, faz-se necessário observar a dinâmica relativa ao desenvolvimento no país. Construiu-se um modelo de Estado intervencionista no Brasil, após a década de 1930, pautado pela 
reestruturação de uma rede de bancos oficiais para financiar o processo de acumulação do novo modelo industrial, bem como pela criação de uma legislação trabalhista, para substituir o modelo agroexportador que dominava a economia pátria até o momento(OLIVEIRA, 1995).

Esse modelo subsistiu até a década de 1980, quando entrou em completo colapso. A crise financeira assolou o Estado desenvolvimentista brasileiro que parecia perecer diante do acúmulo das dívidas interna e externa e frente ao fenômeno hiperinflação. Junto à crise econômica, vinha a instabilidade política de um Estado que acabara de ter sua reabertura democrática em meio a mudanças de cunho neoliberal em todo o continente latino-americano. Nesse contexto, se deu o final da gestão Sarney (SOARES, 2001).

O marco histórico da efetiva inserção brasileira no contexto neoliberal, deu-se com o Consenso de Washington, ocorrido em 1989. O governo estadunidense e o Fundo Monetário Internacional (FMI) condicionaram o fornecimento de ajuda financeira à adoção de uma cartilha de austeridade que reduzisse o tamanho do Estado e abrisse a economia ao mercado, pautada pela fórmula de desregulamentação para aumento de produtividade (TEIXEIRA, 1998).

Com os "planos de estabilização", tais medidas começaram a materializar-se ao longo do Governo Collor. As políticas públicas sofreram um desmonte e houve reflexos diretos para a população mais vulnerável. Sob a condição de interinidade, Itamar Franco passou dois anos à frente do governo, no pósimpeachment. Nesse sentido, deu continuidade às medidas de seu antecessor, apesar de se utilizar de um discurso social.

Fernando Henrique Cardoso, ex-Ministro da Fazenda, assumiu a presidência em 1994. O presidente se propunha a acabar com a inflação e reformar a Constituição para flexibilizar relações trabalhistas. Sua atuação política foi pautada pela compressão salarial e pela busca do ajuste fiscal. Promoveu-se, então, diversas privatizações de empresas estatais, além de reformas previdenciária e administrativa (PAULO NETTO, 1999).

A Reforma de Estado no Brasil resultou em transformações. Com a decadência do desenvolvimentismo, tentou-se implantar uma estratégia liberal de desenvolvimento, por uma agenda de reformas centradas no papel do Estado. Por um processo de síntese, o Brasil adquiriu características singulares que combinam aspectos da velha ordem desenvolvimentista com aspectos de uma ordem liberalizante.

A estratégia foi atacar setores organizados da sociedade e apelar à massa desorganizada. O programa se pautava por reformas (administrativa e patrimonial) e abertura econômica, com reforma da conta de capital e da política comercial. As políticas públicas foram pautadas por reformas macroeconômicas e por reforma de Estado, uma agenda microeconômica com mudança institucional de inspiração liberal, de forma estruturada e com apoio de muitos setores. A retórica da reforma de Estado saiu vitoriosa, culminando na hegemonia de uma convenção neoliberal, que culminou em alterações da esfera fiscal, previdenciária, administrativa, patrimonial e privatizações (DELORME, 2014).

A percepção da sociedade brasileira sobre a atuação do Estado era positiva até sua mudança entre as 
décadas de 1980 e 1990, por motivos internos e externos. As empresas estatais, nesse sentido, passaram a ser vistas como produtos ineficientes da intervenção do Estado, visão estimulada pelo domínio do pensamento neoliberal nas organizações internacionais, que detinham grande influência na política brasileira, devido a fragilidade de sua economia (DELORME, 2014).

Embora a conjuntura dos anos 2000 tenha sido diferenciada com o movimento de governos progressistas na América Latina, em que houve uma aproximação da perspectiva de efetividade do projeto constitucional econômico, é preciso registrar que o primeiro mandato do Presidente Lula e o último ano do segundo mandato da presidenta Dilma dialogaram com os preceitos neoliberais, nunca tendo o Estado Brasileiro enfrentado, de fato, o "Deus Mercado" (MARIANO, 2017).

Com a ascensão de Temer à presidência, em 2016, retomou-se a cartilha neoliberal, agindo o governante no sentido contrário à campanha política que o elegera à vice-presidência. Sua primeira medida de austeridade econômica foi a aprovação da Emenda Constitucional $\mathrm{n}^{\circ}$ 95, naquele mesmo ano. Conhecida como "PEC do fim do mundo", o texto previu que, durante 20 anos, as despesas primárias do orçamento público ficarão limitadas à variação inflacionária (HERMIDA; LIRA, 2018).

Ainda sob esse Governo, foi aprovada a Lei $n^{\circ} 13.467 / 2017$, conhecida como "Reforma Trabalhista", cujo objetivo fora combater o desemprego e a crise econômica no país, mas gerou efeitos diversos, como se verá adiante (HERMIDA; LIRA, 2018). Houve ainda a tentativa de implementar uma Reforma da previdência, que sucumbiu diante da rejeição do presidente frente aos escândalos de corrupção, não havendo "ambiente político" para tanto (BENITES, 2017).

Em 2018, a eleição de Bolsonaro legitimou um programa assumidamente liberal, tendo como principais pontos de campanha a abertura da economia para o mercado, uma menor atuação do Estado, o fim de "políticas populistas" e a privatização de empresas estatais, medidas que se encontram em curso e mostram grande similaridade com a cartilha de Washington. Posteriormente às eleições de 2018, acompanhou-se a extinção do Ministério do Trabalho e a Reforma da Previdência, que foi definitivamente aprovada, resultando na Emenda Constitucional nº 103, de 12 de novembro de 2019 (SAFATLE, 2019).

Munidos do discurso que domina o ambiente parlamentar e a grande mídia, tem-se apelado para a Retórica da Intransigência (HIRSCHMAN, 1992) enquanto tese reacionária para sedimentar, através da ameaça, a implementação do retorno às políticas neoliberais de austeridade no Brasil. Partindo do discurso de que "se as reformas não forem aprovadas, o Brasil quebra", muito têm sido aprofundadas as desigualdades no país, conforme se verá da análise que segue.

\subsection{Medidas de austeridade e o âmbito social}

A presente subseção se propõe a confrontar os efeitos das medidas de austeridade econômica de cunho neoliberal com o projeto constitucional de desenvolvimento com fins de aferir seus reflexos na desigualdade social brasileira. 
No panorama constitucional brasileiro, a Carta de 1946 foi a primeira a incorporar o tema do desenvolvimento, com ênfase na redução dos desequilíbrios regionais, o que passou a constar em todas as Constituições seguintes. Os dispositivos relativos à Ordem Econômica e Social apresentavam a intervenção estatal como forma de corrigir as falhas de mercado (BERCOVICI, 2009).

Assim, cumpre atentar para a ordem-econômica e social brasileira, estabelecida na Carta Política de 1988. É necessário observar que ela nasce após um período político ditatorial e, sob o paradigma do Neoconstitucionalismo, em que a Constituição passa a ser o centro do ordenamento jurídico. Assim, a Lei maior brasileira deixou de ser uma mera declaração de intenções políticas, para tornar-se norma jurídica superior(BARROSO, 2015).

Fato é que a Constituição se ocupou de proteger e garantir uma série de direitos fundamentais. É possível destacar a ideia de dignidade da pessoa humana e os valores sociais do trabalho e da livre iniciativa, enquanto princípios e a construção de uma sociedade livre, justa e solidária; a erradicação da pobreza; a redução das desigualdades sociais e regionais; e a promoção do bem-estar enquanto princípios fundamentais (BRASIL, 1988).

Houve uma preocupação em sinalizar para direitos sociais e econômicos em espécie, tal como enuncia o art. $6^{\circ}$ da CF/88. São direitos sociais a educação, a saúde, a alimentação, o trabalho, a moradia, o transporte, o lazer, a segurança, a previdência social, a proteção à maternidade e à infância e a assistência aos desamparados, dentre outros exemplos a serem citados (BRASIL, 1988).

No art. 170 do referido diploma legal, tratou-se dos princípios gerais da atividade econômica, sendo possível depreender do texto que a atividade econômica no Brasil é fundada na valorização do trabalho humano e na livre iniciativa, sendo que a finalidade desta é assegurar a todos uma existência digna, conforme os ditames da justiça social. Dentro disso, percebe-se uma opção pelo sistema capitalista, embora ele não vigore de forma pura e irrestrita, eis que as finalidades da ordem econômica são à dignidade humana e a justiça social (BERCOVICI, 2009).

Partindo disso, nota-se que a aproximação de realidade fática e do projeto constitucional de desenvolvimento depende da vontade política, de acordo com alternância dos governos, podendo ser democrática ou não. $\mathrm{O}$ balanceamento entre livre iniciativa e justiça social é que conduz as diretrizes do Governo no sentido de atuar na economia e promover a garantia de direitos, através de políticas públicas (TENDLER, 2017).

Há uma dificuldade de mensurar quanto de tais decisões reside na seara política ou se alinha às decisões dos detentores do poder econômico, atores principais do capitalismo, como bancos e grandes empresas, que controlam o país através dos lobbys e da dívida pública. Além disso, é necessário aferir a eficácia das fórmulas prontas de austeridade em tempos de capitalismo financeiro no sentido de geração de investimentos e empregos como é prometido (TENDLER, 2017).

Desde os primórdios do liberalismo, até os dias hoje, tem-se insistido no argumento falacioso de que a maximização da riqueza no geral, trará benefícios particulares a vida dos indivíduos. Entretanto, a Análise 
Econômica do Direito tem conduzido à conclusão de que a eficiência econômica, por si só, não pode ser critério de Justiça, avaliando-se direitos através dos cálculos de custo e benefício (SALAMA, 2017).

Em razão disso, tem-se compreendido o Direito enquanto fator de regulação da atividade econômica para a concretização de políticas públicas. Nesse sentido, interdisciplinarmente, Direito e Economia têm buscado definir a justificativa econômica para a ação pública e uma análise realista das instituições jurídicas. Assim, faz-se possível, empreender uma análise das medidas de austeridade enquanto fator condicionante da desigualdade social no país.

Em primeiro ponto, remonta-se ao neoliberalismo brasileiro dos anos de 1990. O que se obteve como resultado dos planos de estabilização de Collor, foram reflexos para a população mais vulnerável, eis que desemprego e inflação aumentaram e as políticas públicas sofreram um verdadeiro desmonte, sendo este o primeiro ataque às prescrições sociais contidas na recente Constituição Federal de 1988 (PAULO NETTO, 1999).

No tocante a atuação de FHC, tem-se que as medidas que não surtiram os efeitos esperados e acabaram resultando em redução de investimentos sociais, o que atingiu diretamente a massa dos trabalhadores, justamente a que mais demanda os direitos sociais. Dentro disso, a agenda de austeridade do período não culminou no crescimento econômico planejado e a realidade social em muito se afastou dos preceitos da dignidade da existência e da justiça social, sendo incompatíveis com a Ordem Social e Econômica constitucionalmente estabelecida (ANTUNES, 2005).

Por outro lado, nos governos Lula/Dilma, percebeu-se uma aproximação embrionária de realização do projeto constitucional, com efetivação dos direitos sociais previstos na $\mathrm{CF} / 88$. Neste período, no que concerne à educação, habitação, infraestrutura, e redução das desigualdades, foram grandes os avanços (CAMPELLO etal, 2018).

Essa correlação de forças entre o social e o econômico ocasionou debates sobre o retorno da ideologia desenvolvimentista de forma repaginada. Entretanto, tal política também foi comemorada pelas classes dominantes, os lucros e os juros capitalistas foram recorde, gerando um clima de otimismo e apoio de aliados internos e externos, junto ao apassivamento das lutas da classe trabalhadora diante da política transformista do Partido dos Trabalhadores (CASTELO, 2012).

Quanto aos efeitos das medidas austeras do governo Temer, são sentidas as consequências da "EC do teto dos gastos" nas políticas públicas de cunho social, como o sucateamento do SUS e do sistema de educação com pública, com aprofundamento de tal realidade no governo Bolsonaro. Já a reforma trabalhista, segundo relatório do Ministério Público do trabalho (2018), destroçou o princípio da proteção do hipossuficiente nas relações de Trabalho, dificultou o acesso à justiça e desmontou a atuação dos sindicatos, culminando em total precarização de tais relações.

É necessário atentar-se para o fato que as políticas que se tem desenvolvido no país sinalizam para grandes violações de direitos sociais, conduzem para o estado de exceção econômico do capitalismo do desastre, pois as desigualdades sociais geradas para alcançar o ajuste fiscal, podem desembocar em 
consequências nefastas com graves aprofundamentos das desigualdades sociais existentes (MARIANO, 2017).

Esse estado é aquele no qual os países periféricos ficam restritos ao decisionismo de emergência para salvar os mercados, o que se dá através da tutela dos poderes constitucionais. Trata-se de uma sujeição do direito interno às necessidades do capital financeiro. Assim, a periferia vive uma exceção econômica permanente, contrariando ao ambiente de normalidade que ocorre nos países do centro do capitalismo (BERCOVICI, 2004).

Se existe o argumento de que os ajustes neoliberais são capazes de conduzir ao crescimento econômico e ao "desenvolvimento" do país, ele se dá dentro da perspectiva ortodoxa que mede o desenvolvimento de um Estado através de índices pré-fabricados, exclusivamente ligados às perspectivas econômicas estritas e que, ao mesmo tempo, fecha os olhos para a realidade da população, que padece diante da pauperização em massa e falta de acesso a direitos sociais básicos.

Apesar de dolorosa, a conclusão de que o mundo maravilhoso do liberalismo se utiliza de uma igualdade aparente que fica só no discurso para encobrir um mundo de luta e desigualdade, através da exploração do trabalho se faz necessária, partindo-se de uma visão influenciada pela teoria marxista e pachukanista.

O pacote neoliberal tem colocado toda a carga de sacrifício social na parcela economicamente mais vulnerável da sociedade com as reformas que tem adotado o Estado brasileiro, mostrando-se flagrante o aprofundamento da desigualdade no país. Dentro dessa perspectiva, faz-se necessário apelar para outras facetas do conceito de Desenvolvimento no sentido de trazer outras possibilidades para buscar reverter o quadro apresentado.

Surge a demanda de um desenvolvimento que pressupõe a ampliação das liberdades básicas, através da inclusão social e da promoção de direitos. Tal somente poderia se dar com as remoções às restrições de liberdade da escolha racional das pessoas por meio do acesso à educação, à saúde e à verdadeira participação política.

Essa liberdade através do exercício de direitos é o caminho para o desenvolvimento, através de um modelo contra hegemônico, o que nos parece o contrário do caminho traçado pelo Estado brasileiro. É dentro deste espírito que se passa ao estudo da austeridade enquanto fator que limita as liberdades, especialmente a feminina, e aprofunda a desigualdade de gênero no Brasil.

\subsection{Medidas de austeriadade e desiguldade de gênero}

A próxima subseção, dentro da perspectiva de desigualdade, busca compreender como as medidas de austeridade influenciam o âmbito do gênero. Numa tentativa de alcançar o condicionamento proposto pelo escopo do presente trabalho, determinadas condições oriundas da política neoliberal não devem passar despercebidas mediante sua integralização no sistema político, econômico, social e jurídico. 
Nesse sentido, referir-se, principalmente, às circunstâncias que envolvem a condição da mulher brasileira e as problemáticas que circundam determinada temática, além de serem imprescindíveis para o entendimento íntegro dos impactos que essa medida organizacional causa, também busca explicitar um sentido que perpasse os parâmetros de uma análise segmentada.

Segundo García-Granero (2018), nas economias neoliberais e financeirizadas, as reivindicações por redistribuição e representação são impossíveis, havendo uma crise de legitimação do neoliberalismo, dentro uma crise sistêmica contraposta a um projeto emancipador em que a libertação das mulheres seja parte da visão de uma sociedade solidária.

Assim, faz-se necessário ressaltar não somente as informações cabíveis as políticas de austeridade na sua aplicação mais característica, mas também entender, categoricamente, o processo que se desenvolve através dela. Nas questões econômicas, especificamente, o contingenciamento tenta pautar-se sobre o alicerce de uma crise econômica para, assim, adotar medidas administrativas de caráter regressivo, uma vez que o Estado, nesse processo, não ocupa espaço como órgão regulamentador.

Segundo dados de 2019 do Programa das Nações Unidas para o Desenvolvimento (PNUD/ONU), $7,4 \%$ da população brasileira vive na extrema pobreza, a renda per capita é de $\mathrm{R} \$ 1.268,00$ e o índice de Desenvolvimento Humano (IDH) é 0,759. O Relatório de Desenvolvimento Humano (RDH/2019) destaca o tema da desigualdade nos distintos grupos populacionais (PNUD, 2019).

Em relação a 2017, o Brasil apresentou crescimento de 0,001 em seu IDH, caindo uma posição no ranking e sendo o $79^{\circ}$ dentre 189 países, atrás de Chile, Argentina e Uruguai. O dado mais alarmante é que a parcela dos $10 \%$ mais ricos concentra cerca de $42 \%$ da renda total do país, sendo o conjunto final de recomendações do documento voltadas para a questão da desigualdade(PNUD, 2019).

Sobre a questão da desigualdade de gênero, o relatório aponta que, dentre os grupos desprivilegiados sistematicamente, o maior é das mulheres, eis que a disparidade relacionada ao gênero é uma das mais arraigadas formas de desigualdade. Assim, a desigualdade de gênero é uma das maiores barreiras ao desenvolvimento humano. Esse fator se acentua na divisão do poder que os homens e as mulheres exercem no lar, no local de trabalho e na política (PNUD, 2019).

Voltando-se para o Brasil, ao se analisar os dados da Pesquisa Nacional por Amostra de Domicílios Contínua (PNAD Contínua) do Instituto Brasileiro de Geografia e Estatística (IBGE) relativos ao primeiro trimestre de 2020, percebe-se que a taxa de desocupados era de 12,9 milhões, perfazendo uma taxa de 11,9\%, além de 4,8 milhões de desalentados e uma taxa de subutilização de 24,4\%.

No que concerne às diferenças entre homens e mulheres, percebe que, em relação às pessoas com 14 anos ou mais, as mulheres superavam os homens na distribuição percentual de pessoas desocupadas, sendo a diferença de 50,9\% para 49,1\%. Já o número de pessoas na mesma faixa etária fora da força de trabalho se mostrava um dado mais alarmante, posto que as mulheres eram 64,2\% e os homens 35,8\% (IBGE, 2020). Uma hipótese para explicar esse dado é que mulheres normalmente ficam no cuidado dos filhos, idosos e familiares, em grau muito superior aos homens, trabalho exercido sem remuneração e que impede o trabalho 
fora do lar(BIROLI, 2018).

Por último, a taxa de desocupação ficava em proporção de 16,8 para mulheres, enquanto a dos homens era de 12,8 (IBGE, 2020). Ressalte-se que foi selecionado o período do primeiro semestre de 2020 para a análise de tais dados posto que a Pandemia do novo Covid-19 ainda não tinha produzido efeitos na economia que levariam a outras variáveis não pertinentes ao trabalho.

Ante a esses dados, necessário observar a persistência de um modelo econômico pautado na perspectiva da austeridade, que não poderia adotar medidas que fossem diferentes daquelas já encontradas no processo histórico como, por exemplo, a disseminação de uma ideologia pessoal-individual que, mais tarde, seria utilizada como argumento principal para justificar as deficiências do setor público.

Nesse sentido, no que se refere especificamente as questões de gênero, a partir do momento em que se aceita o diferente impacto desses fatores sobre a vida das mulheres brasileiras, considera-se a divisão sexual do trabalho um fator determinístico para o fomento de tal processo.

Para Biroli (2018), a divisão sexual do trabalho é a atribuição histórica de "trabalho de mulher", "lugar de mulher" no mundo laboral. Essa divisão influencia diretamente nas hierarquias de gênero, raça e classe, produzindo vantagens e desvantagens. Embora, entre os anos de 1970 e o início do séc. XXI, o percentual de mulheres economicamente ativas tenha se alterado significativamente, isso não alterou o fato de que o rendimento médio das mulheres ainda é menor do que o dos homens (BIROLI, 2018).

Ademais, é necessário salientar que as mulheres brancas ficam mais próximas dos padrões de oportunidades dos homens brancos, superando os homens negros. As mulheres não-brancas e seus filhos continuam sendo as mais desprivilegiadas, o que demonstra que a divisão sexual do trabalho atua juntamente com os as posições de classe e o racismo estrutural. Feitas tais ponderações, se faz possível dizer que o trabalho precarizado, uma marca neoliberal, atinge as mulheres com maior intensidade (BIROLI, 2018).

Como dito por Dweck; Oliveira; Rossi (2018, p. 51):

\begin{abstract}
Em tempos de austeridade, o tempo e o trabalho das mulheres são as variáveis de ajuste, provendo por meio de bens e serviços o sustento de suas famílias, transferindo para o âmbito privado as responsabilidades do Estado. A fragilização dos serviços públicos é a fragilização da participação das mulheres na política pública como enfermeiras, professoras, assistentes sociais, mas, para além disso, são as mulheres as mais prejudicadas pelos cortes sociais, dada a desigualdade da repartição do trabalho doméstico por gênero que persiste na sociedade brasileira.
\end{abstract}

Essas questões, em sua profundidade, se tornam mais sólidas e presentes ao considerar, por exemplo, que a existência de cortes orçamentários em programas de cunho social tende a atingir, especificamente, a população feminina, uma vez que o processo de crescimento da autonomia feminina no Brasil possui um histórico recente e que está ligado, em sua maior parte, a Secretaria de Política para Mulheres. Nesse caso, é importante ressaltar que esse último, em sua categorização, teve sua autonomia jurídica rebaixada de Ministério para ter suas atribuições divididas em outras pastas (BRASIL, 2019).

Essas mudanças, no entanto, não acontecem e se desenvolvem somente no caráter social do processo 
por isso, entender que o impacto de uma crise econômica sobre diferentes parcelas de uma mesma população, acertadamente, manifesta diferentes resultado. Para essa sintetização, faz-se necessário acompanhar de perto alguns indicadores característicos que existem como consequência a estes como, por exemplo, as taxas de ocupação e rendimento tabeladas por gênero e etnia que podem ser observados na tabela abaixo.

Tabela 01: Taxa de desocupação entre brasileiros ano de 2015 - Por Gênero/Etnia

\begin{tabular}{ccc}
\hline Grupo & Branca & Preta ou Parda \\
\hline Homens & 7,8 & 8,5 \\
\hline Mulheres & 11,6 & 13,3 \\
\hline Total & 19,4 & 21,8 \\
\hline
\end{tabular}

FONTE: IBGE, Pesquisa Nacional por Amostra de Domicílios Contínua. (2015)

Os dados estatísticos, por sua vez, trabalham numa perspectiva geral, revelando a diferença entre homens e mulheres no sentido de sua desocupação. Por vias de análise e pela forma em que este se enquadra como um complemento científico para a temática estudada, o recorte étnico-racial também aparece empregado como instrumento de investigação empírica. Nesse sentido, é possível constatar o impacto social existente ao considerar a dissemelhança das taxas existentes das mulheres negras para os outros delineamentos, uma vez que dentro de sua mesma categoria de análise, o gênero. A diferença se justifica totalmente sobre a questão racial, chegando a quase $2 \%$.

Nessa condição, confrontar os dados a partir de uma análise linear e histórica se coloca como ferramenta essencial não somente para compreender a existência do processo de desigualdade agravado pelas medidas de austeridade, mas também para entender sua dimensão frente ao tema proposto.

Tabela 02: Taxa de desocupação entre mulheres brasileiras ano de 2017 - Por Gênero/Etnia

\begin{tabular}{ccc}
\hline Grupo & Branca & Preta ou Parda \\
\hline Mulheres & 12,4 & 18,9 \\
\hline Total & 12,4 & 18,9 \\
\hline
\end{tabular}

FONTE: IBGE, Pesquisa Nacional por Amostra de Domicílios Contínua. (2017)

Ainda utilizando os dados disponibilizados pela PNAD, permeia-se a condição de um agravamento constante nesses indicadores o que pode ser justificado empiricamente pelas medidas aqui já citadas. Analisando a tabela, é possível explicitar não somente o crescimento dessas taxas num período de 2 (dois) anos, mas, para além disso, dimensioná-lo. Ainda que apenas com uma diferença de dois anos, os dados encontrados na mesma categoria de análise, em 2015, já não se colocam de forma cientificamente representativa, uma vez que seu percentual mostrou um crescimento de quase $7 \%$.

A fim de complementar o que foi dito, Dweck; Oliveira; Rossi (2018, p. 72):

No primeiro trimestre de 2017, conforme dados da PNADC 55, a desocupação no Brasil atingiu recorde com 14,1 milhões de pessoas sem emprego. Deste total, as 
mulheres representavam 50,6\% e, dentre elas, as mulheres negras, 63,2\%. As taxas de desocupação também seguem mais desfavoráveis às mulheres, em especial as negras. Entre os anos de 2012 e 2017, o menor percentual de mulheres desempregadas foi registrado em 2014 com a taxa de 6,2\% para as mulheres brancas e 9,2\% para as mulheres negras, mesmo assim superior a taxas masculinas.

Dessa forma, é possível vislumbrar que as políticas de austeridade refletem socialmente em grupos específicos, atentando-se para os recortes de gênero e raça. Percebe-se, assim, um distanciamento da política econômica do projeto constitucional de desenvolvimento em uma perspectiva ampliada que leve em conta especificidades e liberdades democráticas.

\section{CONSIDERAÇÕES FINAIS}

Conforme foi visto ao longo dessa pesquisa, a política neoliberal se desenvolveu no Brasil, por meio de uma agenda de caráter liberal, na década de 1990, por meio de Reformas que alteraram a posição do Estado e sua forma de atuação na economia, sendo construída uma hegemonia desse pensamento, e vem sendo retomada com intensidade, desde o ano de 2016, a partir de políticas que subtraem direitos da população trabalhadora, que é a mais tem necessidade de políticas públicas e atenção social.

Foi possível perceber que essa atuação governamental se traduziu em fatores condicionantes para a desigualdade social no país, eis que contraria o projeto constitucional de desenvolvimento e desrespeita sistematicamente direitos fundamentais, levando em consideração apenas fatores aferíveis economicamente para analisar o desenvolvimento, sem tomar por base os critérios de Justiça Social e Dignidade Humana. Dentro disso, a Emenda Constitucional do Teto dos Gastos, a Reforma Trabalhista e a Reforma da Previdência se mostram medidas que pioram a condição de vida da população e contrariam a ideia ampliada de desenvolvimento, que requer inclusão social e democrática.

Notou-se também que essa política tem apresentado resultados catastróficos, principalmente para as populações mais vulneráveis. Dentro disso, investimentos sociais e direitos sociais têm sido subtraídos. E o que se percebe é que as fórmulas de austeridade não têm sido eficazes para recuperar a economia, tampouco gerar investimentos e aumentar os empregos.

Isso se dá no panorama do capitalismo financeiro, em que soluções simplistas se mostram insuficientes para responder a problemas oriundos de crises econômicas de caráter global. A experiência, ao contrário do que tem sido feito, demonstra a necessidade de maior investimento estatal para a superação de crises.

Com isso, é possível argumentar que, de fato, as políticas de arrocho orçamentário pautados sobre uma política de austeridade voltado para o Setor Público corroboram com o aumento significativo da desigualdade social no Brasil. Sabe-se que o Brasil é um país desigual desde de sua origem remota devido a forma de sua inserção no capitalismo mundial, o que não se pode tolerar é que tais desigualdades continuem se perpetuando devido a políticas incompatíveis com as singularidades nacionais e com as previsões 
objetivas da Constituição Federal.

Uma vez considerando seus trâmites sociais, econômicos e jurídicos, é perceptível o aumento de indicadores que trabalham diretamente com essas questões como é o caso, por exemplo, das taxas de ocupação tabeladas por gênero e etnia o que reforça, especificamente, as desigualdades sociais pautadas sobre a problemática de gênero e a divisão sexual do trabalho. Por essa razão, salienta-se a necessidade de atentar para esses recortes, demonstrando que a desigualdade social se amplia de diferentes formas e se aprofunda ainda mais em relação às minorias.

Considerando-se uma visão de desenvolvimento que se atente para fatores específicos capazes de aumentar as potencialidades humanas, reduzir disparidades e construir uma sociedade justa e solidária, seria possível contrariar a tradição de desigualdade brasileira, rompendo com esse histórico que afeta em diferentes graus, mas todos igualdade importantes, os gêneros, as classes e raças no Brasil.

\section{REFERÊNCIAS BIBLIOGRÁFICAS:}

ANDRADE, Daniel Pereira. O que é o neoliberalismo? A renovação do debate nas ciências sociais. Soc. estado., Brasília, v. 34, n. 1, pág. 211-239, janeiro de 2019. Disponível em $<$ ht t p://www.scielo.br/scielo.php? script=sci_arttext\&pid=S0102$69922019000100211 \& \operatorname{lng}=\mathrm{en} \& \mathrm{nrm}=\mathrm{iso}>$. acesso em 30 de dezembro de 2020.

ANTUNES, Ricardo. A desertificação neoliberal no Brasil (Collor, FHC e Lula). 2 ed. Campinas: Autores Associados, 2005.

BARROSO, Luís Roberto. Curso de Direito Constitucional Contemporâneo. São Paulo: Saraiva, 2015.

BIROLI, Flávia. Gênero e Desigualdades: os limites da democracia no Brasil. São Paulo: Boitempo, 2018 .

BRASIL. Constituição (1988). Constituição da República Federativa do Brasil. Brasília, DF: Senado Federal: Centro Gráfico, 1988.292 p.

BRASIL. PORTARIA No 3.136, DE 26 DE DEZEMBRO DE 2019. Aprova o Regimento Interno do Ministério da Mulher, da Família e dos Direitos Humanos. Brasília: 2019. Disponível em: https://www.in.gov.br/web/dou/-/portaria-n-3.136-de-26-de-dezembro-de-2019-*-237663194. Acesso em: 15 de nov 2020.

BENITES, Afonso. Gravação da JBS coloca Governo Michel Temer à beira do abismo. El País. Brasília, 18 d e $\mathrm{m}$ a $\mathrm{i}$ o 20017. D i s p o n íve 1 e $\mathrm{m}$ : https://brasil.elpais.com/brasil/2017/05/18/politica/1495072574_653336.html.Acesso em: 15 de nov 2020. BERCOVICI, G. Constituição e Estado de Exceção Permanente: Atualidade de Weimar. Rio de Janeiro: Azougue, 2004. 
BERCOVICI, Gilberto. Tentativa de instituição de democracia de massas no Brasil: instabilidade constitucional e direitos sociais na Era Vargas (1930-1964). In: FONSECA,

Ricardo; SEELAENDER, Airton (org.). História do Direito em perspectiva: do Antigo Regime à modernidade. Curitiba: Juruá, 2009, p. 375-414.

CAMPELO, Tereza; GENTILI, Pablo; RODRIGUES, Monica; HOEWELL, Gabriel Rizzo. Faces da desigualdade no Brasil: um olhar sobre os que ficam para trás. Saúde debate [online]. 2018, vol.42, n.spe3, pp.54-66. ISSN 0103-1104. http://dx.doi.org/10.1590/0103-11042018s305.

CASTELO, Rodrigo. O novo desenvolvimentismo e a decadência ideológica do pensamento econômico brasileiro. Serv. Soc. Soc., São Paulo, n. 112, p. 613-636, Dec. 2012. Disponível em: http://www.scielo.br/scielo.php?script=sci_arttext\&pid=S0101-66282012000400002\&lng=en\&nrm=iso. Acesso em 10 ago. 2020.

DWECK, Esther; OLIVEIRA, Ana Luíza Matos de; ROSSI, Pedro. Austeridade e retrocesso: impactos sociais da política fiscal no Brasil. São Paulo, 2018.

GARCÍA-GRANERO, Marina. Injusticias de género em tiempos de neoliberalismo: el planteamiento de Nancy Fraser. Asparkía, 33; 2018, ISSN: 1132-8231 - DOI 10.6035, p. 207-223. Disponível em: http://repositori.uji.es/xmlui/bitstream/handle/10234/181053/Garcia_Injusticias.pdf?sequence=1\&isAllow ed=y. Acesso em 29 dez. 2020.

GIL, Antônio Carlos. Como elaborar projetos de pesquisa. 4. ed. São Paulo: Atlas, 2008.

GUSTIN, Miracy Barbosa de Sousa; DIAS, Maria Teresa Fonseca. (Re)pensando a pesquisa jurídica: Teoria e Prática. 2. ed., Belo Horizonte: DelRey, 2006.

HERMIDA; Jorge Fernando; LIRA, Jailton de Souza. Estado e Neoliberalismo no Brasil (1995-2018). Cadernos de Pesquisa Pensamento Educacional. Curitiba, v. 13, n. 35, set/dez de 2018. ISSN 1980-9700. Disponível em: https://interin.utp.br/index.php/a/article/view/2027. Acesso em: 14 nov. 2020.

HIRSCHMAN, Albert O. A retórica da intransigência: perversidade, futilidade, ameaça. São Paulo: Companhia das Letras, 1992.

INSTITUTO BRASILEIRO DE GEOGRAFIA E ESTATÍSTICA (IBGE). Pesquisa Nacional por Amostras de Domicílios Contínua: desemprego no primeiro trimestre de 2020. IBGE, [s. 1], 2020. Disponível em: https://www.ibge.gov.br/estatisticas/sociais/trabalho/9173-pesquisa-nacional-por-amostrade-domicilios-continua-trimestral.html?edicao=27704\&t=destaques. Acesso em: 29 de ago. 2020.

MARIANO, Cynara Monteiro. Emenda constitucional 95/2016 e o teto dos gatos públicos: Brasil de volta ao estado de exceção econômico e ao capitalismo do desastre. Revista de Investigações Constitucionais, Curitiba, vol. 4, n. 1, p. 259-281, jan./abr. 2017. DOI:10.5380/rinc.v4i1.50289. 
MARX, Karl. Contribuição à crítica da economia política. São Paulo: Expressão Popular, 2008.

MARX, Karl. Para questão judaica. Tradução: José Barata Moura. São Paulo: Expressão Popular, 2009.

MINISTÉRIO PÚBLICO DO TRABALHO. MPT seminário sobre efeitos da reforma trabalhista. Brasília: 14 de set de 2018. Disponível em: http://portal.mpt.mp.br/wps/portal/portal_mpt/mpt/salaimprensa/mpt-noticias/5546c410-6f31-457b-8654-4dad76df32c1. Acesso em 24 de fev 2019.

OLIVEIRA, Francisco. Neoliberalismo à brasileira. In: SADER, Emir \& GENTILI, Pablo (Orgs.) Pósneoliberalismo: as políticas sociais e o Estado democrático. Rio de Janeiro: Paz e Terra, 1995, p. 24-28.

PAULO NETTO, J. FHC e a política social: um desastre para as massas trabalhadoras. In: LESBAUPIN, Ivo (Org.) O desmonte da nação: balanço do governo FHC. $3^{\text {a }}$ ed. Petrópolis; Rio de Janeiro: Vozes, 1999.p. 75-89.

PAULO NETTO, José Paulo. O que é marxismo. 9. ed. 2. reimpressão. São Paulo: Brasiliense, 2009.

PNAD, IBGE. PESQUISA NACIONAL POR AMOSTRA DE DOMICÍLIOS. Rio de Janeiro: IBGE, 2015 .

PNAD. PESQUISA NACIONAL POR AMOSTRA DE DOMICÍLIOS. Rio de Janeiro: IBGE, 2017.

POMAR, Walter. O desenvolvimento e a soberania nacional. In: Congresso Nacional de Sindicatos de Engenheiros, $11^{\circ}$, 2017, Curitiba. Caderno de Teses. Resistir em Defesa da Soberania e da Engenharia Nacional. Curitiba: Federação Interestadual de Sindicatos de Engenheiros, 2017. p. 29-63.

PROGRAMA DAS NAÇÕES UNIDAS PARA O DESENVOLVIMENTO (PNUD). Relatório de Desenvolvimento Humano de 2019. Além da renda, além das médias, além de hoje: desigualdades no desenvolvimento humano no século XXI. PNUD, [s. 1], 2019. Disponível em: http://hdr.undp.org/sites/default/files/hdr_2019_pt.pdf.Acesso em: 29 de ago. 2020.

SAFATLE, Vladmir. A ditadura do sr. Guedes. El País, Rio de Janeiro, 05 de dec 2019. Disponível em: https://brasil.elpais.com/opiniao/2019-12-05/a-ditadura-do-sr-guedes.html. Acesso em: 15 de nov de 2020.

SALAMA, Bruno Meyerhof. Análise econômica do direito. Enciclopédia jurídica da PUC-SP. Celso Fernandes Campilongo, Alvaro de Azevedo Gonzaga e André Luiz Freire (coords.). Tomo: Teoria Geral e Filosofia do Direito. Celso Fernandes Campilongo, Alvaro de Azevedo Gonzaga, André Luiz Freire (coord. de tomo). São Paulo: Pontifícia Universidade Católica de São Paulo, 2017. Disponível em: https://enciclopediajuridica.pucsp.br/verbete/41/edicao-1/analise-economica-do-direito

SOARES, L. Tavares. Ajuste neoliberal e desajuste social na América Latina. Petrópolis; Rio de Janeiro: Vozes, 2001.

TEIXEIRA, F. José. O neoliberalismo em debate. In: TEIXEIRA, F. Jose (Org.) Neoliberalismo e 
reestruturação produtiva: as novas determinações do mundo do trabalho. $2^{\mathrm{a}}$ ed. São Paulo: Cortez, 1998, p. $195-252$.

TENDLER, Sílvio. Dedo na ferida. Direção: Silvio Tendler. Brasil, 2017. Documentário (90 min), colorido, disponível em: https://www.youtube.com/watch?v=tRdhOrcmRHQ. Acesso em: 20 de fev. 2019.

VALENÇA, Daniel Araújo; CAVALCANTE; Giulia Maria Janelle; FREITAS, Júlia Maria dos Santos de. Marxismo e América Latina: aportes para a compreensão de um continente em luta. In: VALENÇA, Daniel Araújo; MAIA JÚNIOR, Ronaldo Moreira; GOMES, Rayane Cristina de Andrade. Marxismo e América Latina: lutas políticas e novos processos constituintes. Rio de Janeiro: Lumen Juris, 2019, p. 1-18. 